\title{
Gross Motor Coordination and Weight Status of Portuguese Children Aged 6-14 Years
}

\author{
ANTÓNIO M. ANTUNES ${ }^{1}$ JOSE A. MAIA ${ }^{2}$ MIKIS D. STASINOPOULOS ${ }^{3}$ ELVIO R GOUVEIA,${ }^{1}$ MARTINE A. THOMIS, ${ }^{4}$ \\ JOHAN A. LEFEVRE ${ }^{4}$ ALEXANDRA Q TEIXEIRA, ${ }^{1}$ AND DUARTE L. FREITAS ${ }^{1,5 *}$ \\ ${ }^{1}$ Department of Physical Education and Sports, University of Madeira, Funchal, Portugal \\ ${ }^{2} \mathrm{CIFI}^{2} \mathrm{D}$, Faculty of Sport, University of Porto, Porto, Portugal \\ ${ }^{3}$ STORM, FLSC, London Metropolitan University, London, United Kingdom \\ ${ }^{4}$ KU Leuven, Faculty of Kinesiology and Rehabilitation Sciences, Department of Kinesiology, Physical Activity, \\ Sports \& Health Research Group, Leuven, Belgium \\ ${ }_{5}^{5}$ Department of Mathematical Sciences, University of Essex, Colchester, United Kingdom
}

Objectives: To construct age- and gender-specific percentiles for gross motor coordination (MC) tests and to explore differences in gross MC in normal-weight, overweight and obese children.

Methods: Data are from the "Healthy Growth of Madeira Study," a cross-sectional study carried out in children, aged 6-14 years. All 1,276 participants, 619 boys and 657 girls, were assessed for gross MC (Körperkoordinations Test für Kinder, KTK), anthropometry (height and body mass), physical activity (Baecke questionnaire) and socioeconomic status (SES). Centile curves for gross MC were obtained for boys and girls separately using generalized additive models for location, scale and shape.

Results: A significant main effect for age was found in walking backwards and moving sideways. Boys performed significantly better than girls on moving sideways. At the upper limit of the distributions, interindividual variability was higher in hopping on one leg (girls) and jumping and moving sideways (boys and girls). One-way ANCOVA, controlling for age, physical activity and SES, indicated that normal-weight children scored significantly better than their obese peers in all gross MC tests. Overweight boys and girls also scored significantly better than their obese colleagues in some MC tests.

Conclusions: These centile curves can be used as reference data in Portuguese children and youth, aged 6-14 years. Being overweight or obese was a major limitation in MC tests and, therefore, of the children's health- and performancerelated physical fitness.

Given the link between gross motor coordination (MC), physical activity and health-related fitness, a number of academics have gathered factual evidence related to ageand gender-associated variation in gross MC tests (Ahnert et al., 2009; Kiphard and Schilling, 1974; Largo et al., 2003, 2001a,2001b; Vandorpe et al., 2011). From these studies, MC seems to improve with age during middle childhood and adolescence, while there is a lack of consensus about gender-associated differences across age ranges and $\mathrm{MC}$ tests.

A more comprehensive picture of the developmental trajectory of gross MC has recently been provided by Chaves et al. (2013) and Vidal et al. (2009) in Portuguese children, aged 6-11 years. Gross MC was assessed via the "Körperkoordinations Test für Kinder" (KTK) (Kiphard and Schilling, 1974), and the LMS method (Cole and Green, 1992) was used to derive the age- and genderspecific percentiles. Boys and girls not only demonstrated improved MC scores with increasing age, but also showed a large interindividual variability, i.e., a wide absolute range between the $3 \mathrm{rd}$ and 97 th percentiles. Similar results were found by Valdivia et al. (2008a) in Peruvian children, aged 6-11 years, using KTK and the same statistical method to derive gross MC curves.

The aforementioned interrelationships and the developmental trajectories of gross MC are strongly mediated by other variables including weight status, physical activity and SES (D'Hondt et al., 2013; Krombholz, 2013; Stodden et al., 2008; Zahner et al., 2009). Specifically, overweight and obese children were found to perform more poorly on gross MC than their normal-weight peers, with an obvious effect of body mass index (BMI) on weight-bearing gross MC tasks (D'Hondt et al., 2013; 2011a; Gentier et al., 2013; Krombholz, 2013). In addition, the BMI-related differences in gross MC seem to be more pronounced in late childhood (D'Hondt et al., 2011a) than in the beginning of adolescence (Lopes et al., 2012a).

Children with different levels of MC differ in levels of physical activity. For example, Lopes et al. (2011) showed that children within the highest MC group had a higher level of physical activity. Graf et al. (2004) reported that children with the greatest extent of exercise achieved the highest MC level. Sports participation is an important way to increase total physical activity (Zahner et al., 2009) and enhance the development of basic motor skills in children (Malina et al., 2004). Participation in sports has also been associated with higher levels of gross MC (Fransen et al., 2012; Vandorpe et al., 2012), and plays a central role in children's future level of gross MC (D'Hondt et al., 2013).

Studies investigating SES-associated variation in gross MC are less extensive and results vary among them. Among Peruvian boys, those of high and middle SES scored better than low SES peers on jumping sideways (Valdivia et al., 2008b). German children of middle SES had better 
scores on walking backwards, jumping sideways, and hopping on the right and left foot compared to children of higher or lower SES (Krombholz, 2013). In contrast, high SES Flemish girls scored better than low and middle SES on walking backwards, jumping sideways, and hopping on one leg. The four MC tests did not differ significantly by SES among boys (Vandendriessche et al., 2012).

Apart from the recent progress in constructing normative values for gross MC tests, the previous studies of Chaves et al. (2013), Valdivia et al. (2008a), Vandorpe et al. (2011), Vidal et al. (2009), and Largo et al. (2001a, 2001b) were confined to particular countries and there is still a need for well-constructed centile curves. In effect, these studies did not embrace the age band recommended for the KTK battery, i.e., 5-14 years, and did not use statistical modelling that derive growth curves from truncated data, as in the case of walking backwards and hopping on one leg. The current study provides age- and gender-specific percentiles for gross MC tests based on a large representative sample of children. It overcomes some of the earlier failings, namely, an extension of the age interval and a statistically novel approach to derive the centile curves. It was hypothesized that gross MC would improve with increasing age and that genderassociation variation would be associated with the gross MC test. It was our expectation that these centile values could provide a better understanding of the general pattern of gross MC tests and be used by professionals for screening, control, and research purposes.

It is also worth emphasizing that prior research remains inconclusive with regard to the association between BMI and gross MC in late childhood and adolescence. Therefore, we also investigated the differences in gross MC among normal-weight, overweight and obese children after controlling for age, physical activity and SES. It was hypothesized that normal-weight children would outperform their obese peers in all gross MC tests and that these differences would be more marked in late childhood. Furthermore, it was hypothesized that overweight children would surpass their obese peers in weight-bearing tests such as on hopping on one leg and jumping sideways.

\section{SUBJECTS AND METHODS Participants}

This study uses data from the "Healthy Growth of Madeira Study" (HGMS), a cross-sectional study of children, aged 3-15 years, conducted by the University of Madeira and the Government of the Autonomous Region of Madeira in 2005 and 2006. Briefly, 40 public/private schools were randomly selected and stratified according to geographical location (11 districts), school grade (nursery schools/kindergartners and grades 1-9) and school facilities (gym and/or school sports hall). Approximately 50 boys and 50 girls were sampled in each age interval from 3 to 9 years and about 100 boys and 100 girls were sampled from 10 to 14 years. The number of children sampled was proportional to the number of children enrolled in the education system, matched by district, age and sex. A list of schools and students was provided by the Secretary of Education and Culture. Sampling procedures were carried out with the assistance of "Statistics Portugal" and have been reported in detail elsewhere (Freitas et al., 2013).
The Director of each school selected the children randomly until the required number of boys and girls was obtained. Any child with a known disability was excluded. In all, the HGMS comprises a sample of 1,637 voluntary children, 801 boys, and 836 girls. The current study involves a subsample of 1,276 children, 619 boys and 657 girls, which correspond to the total number of children aged 6-14 years who performed KTK. Parents/legal guardians and children gave their informed consent/ assent. The HGMS received approval from the ethics committee of the University of Madeira, educational authorities and local hospital.

\section{Data collection}

Data were collected between January and June 2006, by six teachers of Physical Education under the supervision of the leader of the research team. The field team members underwent theoretical classes and lab sessions during a period of 3 months. A pilot study was carried out in 46 children, age 3-10 years, from a primary school. Children were assessed twice with an interval of 1 week (1st evaluation, 6 and 7 December; 2nd evaluation, 13 and 15 December, 2005) aiming to assess test-retest reliability and to refine the assessment procedures. Anthropometric measurements took place in the gym and MC tests were assessed in the school sports hall. Both, anthropometry and MC tests were assessed/performed in a single day ( $\sim 20$ participants/day).

\section{Anthropometry}

The field team members of the HGMS assessed children's stature and weight following the guidelines of Claessens et al. (1990). Participants wore a swimming costume (two-piece for females), with shoes and jewellery removed. Stature was measured with a portable stadiometer (SiberHegner, GPM) to the nearest millimetre. Weight was measured on a balance-beam scale accurate to $100 \mathrm{~g}$ (Seca Optima 760, Germany). Children were classified as normal-weight, overweight or obese according to the ageand sex-specific BMI [calculated by dividing weight $(\mathrm{kg})$ by height $\left(\mathrm{m}^{2}\right)$ ] cut-off points developed by the International Obesity Task Force (Cole et al., 2000). In the pilot study, the intraclass test-retest correlation coefficient (ICC) and technical error of measurement (TEM) for stature and body mass were $1.000(\mathrm{TEM}=0.315)$ and 0.996 (TEM $=0.661)$, respectively. For the HGMS, corresponding values were 1.000 for stature $(\mathrm{TEM}=0.442)$ and 1.000 for weight $(\mathrm{TEM}=0.437)$.

\section{Gross motor coordination}

The "Körperkoordinations Test für Kinder" (KTK) (Kiphard \& Schilling, 1974) includes four specific tasks: (1) balance while moving backwards - the child is required to walk backwards on balance beams $3 \mathrm{~m}$ in length but of decreasing widths: $6 \mathrm{~cm}, 4.5 \mathrm{~cm}, 3 \mathrm{~cm}$; the number of successful steps is recorded; (2) jumping laterally_with the feet together, the child is required to make consecutive jumps as rapidly as possible from side to side over a small beam $(60 \mathrm{~cm} \times 4 \mathrm{~cm} \times 2 \mathrm{~cm})$ for 15 seconds; the number of correct jumps is recorded; (3) hopping on one leg over an obstacle-the child is required to hop on one foot over a stack of foam squares; after a successful hop (the child clears the foam square without touching it and continues to hop on the same foot at least two times) 
with each foot, the height is increased by adding a square $(50 \mathrm{~cm} \times 20 \mathrm{~cm} \times 5 \mathrm{~cm})$; three attempts at each height and with each foot are given, and the height of the final successful jump was recorded as the score; (4) shifting platforms - with the child standing with both feet on one platform $(25 \mathrm{~cm} \times 25 \mathrm{~cm} \times 2 \mathrm{~cm}$ supported on four legs $3.7 \mathrm{~cm}$ high) and holding a second identical platform in his/her hands, he/she is required to place the second platform alongside the first and to step on to it; the first box is then lifted and placed alongside the second and the child steps on to it (if the child falls off in the process, he/she simply gets back on to the platform and continues the test); the sequence continues for 20 seconds; each successful transfer from one platform to the other is given two points (one for shifting the platform, the other for transfer of the body), and the number of points in 20 seconds was recorded. Raw scores for each of the four tests were used in the current analysis. Test-retest reliability, via ICC, carried out in the pilot study ranged between 0.64 (hopping on one leg) and 0.90 (walking backwards).

\section{Physical activity and socioeconomic status}

Physical activity was assessed by means of a questionnaire developed by Baecke et al. (1982). The questionnaire presents 16 questions, eight of them related to physical activity at work (questions 1-8), four related to sports practice (questions 9-12) and four related to leisure-time physical activity (questions 13-16). Answers to the different items of the questionnaire are quantified in a Likert scale, with the exception of the main occupation and sports. A sport score (one or two main sports) is calculated from a combination of the intensity of the sport that was played, the amount of time played per week, and the yearly proportion of time in which the sport was played regularly. Three indices are operationalized: physical activity at work, physical activity in sports, and physical activity in leisure time. In the present study, work index was not calculated because all participants were students Sport index and leisure-time index were summed and used as total physical activity. Test-retest reliability of the sport and leisure-time indices, measured within the scope of the "Madeira Growth Study" (Freitas et al., 2007) were 0.80 and 0.73 , respectively, and parallels the results found by Baecke et al. (1982) in the original sample of Dutch adult men and women (0.81 and 0.74, respectively). Vasconcelos and Maia (2001) also presented intraclass correlation estimates for physical activity ranging from 0.80 to 0.87 in Portuguese children, aged 10-18 years.

Socioeconomic information was collected via a standardized questionnaire developed by the 'Statistics Portugal' (Instituto Nacional de Estatística, 1995). The questionnaire encompasses five characteristics (parental occupation, education, income, housing, and residential area features), but only education, i.e., the highest educational attainment of the father or mother, was used. The team members filled out the questionnaires (physical activity and socioeconomic) by means of a face-to-face interview. At earlier ages and whenever necessary, the questionnaire was filled out with the assistance of the school's teacher, parents, or tutors.

\section{Centile curves}

Centile curves for gross MC tests were obtained for boys and girls separately using generalized additive models for location, scale and shape (GAMLSS) (Rigby and Stasinopoulos, 2005) and its R implementation (Stasinopoulos and Rigby, 2007). Different distributions were selected using the Akaike information criterion (AIC). For walking backwards and hopping on one leg tests, truncated versions were used because these tasks had an upper limit. For boys, the Normal (or Gaussian) (NO) (truncated), Skew $t$ type 3 (ST3) (truncated), Box-Cox power exponential (BCPE), and Box-Cox $t$ (BCT) distributions were used to fit the growth curves of the walking backwards, hopping on one leg, jumping sideways and moving sideways tests, respectively. For girls, the distributions chosen to model gross MC tests were power exponential (PE) (truncated) (walking backwards), $t$ family (TF) (truncated) (hopping on one leg), and Box-Cox Cole and Green (BCCG) (jumping sideways and moving sideways).

The parameters to be estimated for each distribution were: NO $(\mu, \sigma), \mathrm{PE}, \mathrm{TF}$ and BCCG $(\mu, \sigma, v)$, and ST3, $\mathrm{BCPE}$ and $\mathrm{BCT}(\mu, \sigma, v, \tau)$. The parameter $\mu$ is interpreted as relating to location (median), while $\sigma$ is a scale parameter (approximate coefficient of variation). The other two, $v$, and $\tau$, are shape parameters (transformation to symmetry). All parameters were modelled as smooth functions of age using penalized splines (P-splines) (Eilers \& Marx, 1996). In each case, the smoothing parameters were selected using local maximum likelihood as described by Stasinopoulos and Rigby (2013).

\section{Data analysis}

Data were entered once in the computer by two different people-each person entered the data once, in a total of two entries-and cross-referenced in STATA, version 11 (StataCorp, 2009) to detect input errors. Outliers and the normality of the data were first explored. Descriptive statistics were calculated to determine the means, standard deviations and/or frequencies for age, anthropometry, gross MC, physical activity, and SES. A two-way betweengroups analysis of variance (ANOVA) was used to test simultaneously for the effect of age and gender on each gross MC test and to explore the possibility of any interaction effect; the effect size was reported as partial eta squared $\left(\eta_{p}^{2}\right)$. Analysis of covariance (ANCOVA) was used to explore differences between BMI categories (normalweight, overweight, and obese) on each gross MC tests, while controlling for age, age squared, physical activity and SES. The raw scores of the current sample were compared with national and international samples using onesample $t$-tests. All analyses were performed using STATA, version 11 (StataCorp, 2009) and SPSS 19.0 (IBM Corp, Released 2010). The minimal statistical significance was set at $P<0.05$.

\section{RESULTS}

\section{General characteristics}

Means, SDs, frequencies (absolute and relative) and ranges for the socio-demographic and health variables are presented in Table 1 . In all, $48.5 \%$ of the children are boys and $51.5 \%$ girls. The prevalence of overweight and obesity is $17.69 \%$ and $7.47 \%$, respectively, for the boys, and $20.70 \%$ and $5.02 \%$ for the girls. Approximately 50\% of the parents have secondary or polytechnic/university level education, which parallels the data from 2001 Census. 


\begin{tabular}{|c|c|c|c|c|}
\hline \multirow[b]{2}{*}{ Characteristics } & \multicolumn{2}{|c|}{ Boys } & \multicolumn{2}{|c|}{ Girls } \\
\hline & $n$ & Mean \pm sd & $n$ & Mean \pm sd \\
\hline Age (years) & 619 & $11.20 \pm 2.39$ & 657 & $11.26 \pm 2.38$ \\
\hline Height (cm) & 616 & $146.71 \pm 15.52$ & 657 & $145.98 \pm 13.84$ \\
\hline Body mass (Kg) & 616 & $42.39 \pm 14.30$ & 657 & $41.84 \pm 13.16$ \\
\hline Body mass index (kg/m2) & 616 & $19.14 \pm 3.61$ & 657 & $19.14 \pm 3.62$ \\
\hline Normal-weight & & $461(74.84 \%)^{\mathrm{a}}$ & & $488(74.28 \%)^{\mathrm{a}}$ \\
\hline Overweight & & $109(17.69 \%)^{\mathrm{a}}$ & & $136(20.7 \%)^{\mathrm{a}}$ \\
\hline Obese & & $46(7.47 \%)^{\mathrm{a}}$ & & $33(5.02 \%)^{\mathrm{a}}$ \\
\hline \multicolumn{5}{|l|}{ Physical activity } \\
\hline Sport index (range 1-5) & 614 & $3.04 \pm 0.63$ & 650 & $2.64 \pm 0.58$ \\
\hline Leisure-time index (range 1-5) & 614 & $2.74 \pm 0.59$ & 650 & $2.55 \pm 0.57$ \\
\hline Total (range $2-10)$ & 614 & $5.77 \pm 0.99$ & 650 & $5.19 \pm 0.94$ \\
\hline \multicolumn{5}{|l|}{ Socioeconomic status ${ }^{b}$} \\
\hline Elementary school (grades 1 to 6 ) & & $280(45.53 \%)^{\mathrm{a}}$ & & $317(49.07 \%)^{\mathrm{a}}$ \\
\hline Secondary school (grades 7 to 12 ) & & $213(34.63 \%)^{\mathrm{a}}$ & & $238(36.84 \%)^{\mathrm{a}}$ \\
\hline Post-secondary (polytechnic and university) & & $122(19.84 \%)^{\mathrm{a}}$ & & $91(14.09 \%)^{\mathrm{a}}$ \\
\hline
\end{tabular}

adata are frequencies [absolute $(n)$ and relative $(\%)]$.

${ }^{\mathrm{b}}$ High qualification of the father or mother.

\section{Reference values and centile curves for gross motor} coordination tests

Means, SDs and age-, and gender-specific smoothed percentiles $\left(10^{\text {th }}, 25^{\text {th }}, 50^{\text {th }}, 75^{\text {th }}\right.$, and $\left.90^{\text {th }}\right)$ for gross MC tests are shown in Table 2. Graphical representation is given in Figures $1-4$. Scores on walking backwards $[F(8$, $\left.1258)=41.45, P<0.001, \eta^{2}=0.21\right]$ and moving sideways $\left[F(8,1258)=167.01, P<0.001, \eta_{p}^{2}=0.52\right]$ improve with age among our children, aged $6-14$ years. Furthermore, boys perform better than girls on moving sideways $[\mathrm{F}$ (1, $\left.1258)=34.39, P<0.001, \eta^{2}=0.03\right]$. A significant interaction effect between the age group and the gender is found on hopping on one leg $[F(8,1258)=2.66, P=0.007$, $\left.\eta_{p}^{2}=0.02\right]$ and jumping sideways $[F(8,1258)=2.53$, $\left.P=0.010, \eta_{p}^{2}=0.02\right]$, indicating that the influence of age on these gross MC tests is dependent on sex and, therefore, we cannot safely interpret the main effects.

Age-, and gender-specific differences described earlier are seen in the growth curves. Additionally, for walking backwards (Fig. 1), interindividual variability is similar at 6 and 14 years old. For hopping on one leg, boys show analogous variability at the extremes, but interindividual variability is higher in girls at 14 years (Fig. 2). A greater variability at the upper limit is also seen for jumping sideways and moving sideways in boys and girls (Figs. 3 and 4).

\section{Gross motor coordination and weight status}

Age-, and gender-specific means and SDs for gross MC testes of normal-weight, overweight and obese children, aged 6-14 years, are shown in Table 3. The results of ANCOVAs, controlling for age, age squared, physical activity and SES are presented as well. Children classified as normal-weight outperform their obese peers in all gross MC tests. Overweight boys also score better than obese peers in walking backwards (6-8 years), hopping on one leg (12-14 years) and moving sideways (12-14 years). In addition, overweight girls surpass obese colleagues in walking backwards $(9-11 ; 12-14$ years), hopping on one leg (all age groups) and jumping sideways (12-14 years).

\section{DISCUSSION}

This study provided age- and gender-specific percentiles for gross MC tests and investigated differences in gross MC among normal-weight, overweight and obese children. In detail, raw scores on walking backwards and moving sideways improved with age and boys performed better than girls on moving sideways. Furthermore, normal-weight children outperformed their obese peers in all gross MC tests. Overweight children also surpassed obese colleagues on walking backwards, hopping on one leg, moving sideways (boys), and jumping sideways (girls) in some age groups.

Although centile curves for gross MC tests have been published for Portuguese (Chaves et al., 2013; Vidal et al., 2009) and Peruvian (Valdivia et al., 2008a) children, the growth curves representing developmental changes from 6 to 14 years have apparently not been provided. Notwithstanding, age and gender effects on gross MC tests, via two-way ANOVA, were given in a Belgian sample, aged 611 years. Vandorpe et al. (2011) observed that performance on the four subtests improved significantly with increasing age and post hoc analysis revealed that each age group scored significantly better than their 1-year younger counterparts. Belgian girls also scored better than boys on walking backwards, while boys outperformed girls on hopping on one leg. These data parallel our walking backwards and hopping on one leg samples for the age-related developmental patterns, but are contradictory for gender-related differences.

It is well known that attained levels of performance in a variety of fundamental motor skills, strength, and performance improve with age during childhood and adolescence (Malina et al., 2004) and, therefore, the gradual improvement in gross $\mathrm{MC}$ tests is not surprising as it appears to be a general phenomenon (D'Hondt et al., 2011b; Vandorpe et al., 2011). Of note, is the lack of consensus regarding to gender-related differences. In the original sample, Kiphard and Schilling (1974) reported no differences between boys and girls on walking backwards and moving sideways. These results corroborate what was found in the present study for walking backwards, but not 
for moving sideways. German girls also showed a general advantage over boys on hopping on one leg and jumping sideways. These results did not parallel our sample. In fact, it was expected that boys would score better than girls on jumping or hopping since these tasks require strength, endurance, and explosiveness (D'Hondt et al., 2011b). Nonetheless, considering the positive effect of typical games, such as hopscotch and rope jumping, on jumping tasks, girls have also been found to outperform boys (Vandorpe et al., 2011). Hence, biological and environmental forces might influence the raw scores observed in these $\mathrm{MC}$ tasks, favoring either boys or girls.

In a further attempt to assign a meaning to our results, data from the current study were compared with Belgian (Vandorpe et al., 2011) and German (Kiphard and Schilling, 1974) children. A one-sample $t$-test revealed lower scores in Portuguese boys and girls compared to Belgian counterparts on hopping on one leg and jumping sideways, while the opposite was found for walking backwards ( $t$-statistic and $P$-values not shown). In moving sideways, our boys performed significantly better than Belgian peers at $6,8,9$, and 10 years old, but girls scored lower. A similar trend was observed when using onesample $t$-tests with the German mean as the reference value. Portuguese children scored significantly lower than the German sample for walking backwards (girls), hopping on one leg, jumping sideways, and moving sideways.

This comes as a revelation, given the temporal gap between our study and the German sample ( $\sim 32$ years). It was expected that the increased standard of living, opportunity for practice and instruction, and learning, experienced by the Portuguese children in the last decades, could lead to similar or higher scores of gross MC. However, recent papers also demonstrated that changes in fat mass (Krombholz, 2013), physical activity (Vandorpe et al., 2012), sedentary behavior (Lopes et al., 2012b), and physical fitness (Tomkinson et al., 2012) operating in recent years might potentially explain our findings. Interestingly, scores from the current study were similar or slightly above the Portuguese peers from the Azores (Vidal et al., 2009) and Viseu (Chaves et al., 2013). It is also noteworthy that the large interindividual variation found in this study was corroborated by Chaves et al. (2013) and Vidal et al. (2009) in all gross MC tests.

To explore the effect of fat mass in attained levels of gross MC, children of different weight status were compared. Our findings of decreased gross MC with increased $\mathrm{BMI}$ and the different relationships according to age, gender and gross MC tests were consistent with previous research. A negative association of BMI on hopping on one leg, jumping sideways and moving sideways has been reported by D'Hondt et al. (2011a) in Belgian children, aged 5-12 years. BMI-related differences in gross MC were also more pronounced with increasing age (D'Hondt et al., 2013; 2011a). This trend was not observed in our data. Overweight and/or obesity was also associated with lower scores on gross MC in German (Graf et al., 2004; Krombholz, 2013) and Portuguese (Lopes et al., 2012a) children. It was suggested that overweight and/or obese children perform worse in weight-bearing gross MC tasks because a greater proportion of fat mass has to be supported or moved against gravity (Gentier et al., 2013).

This study has a number of distinctive and innovative features. It uses a novel fitting approach to derive the gross MC curves. A previous use by the World Health 

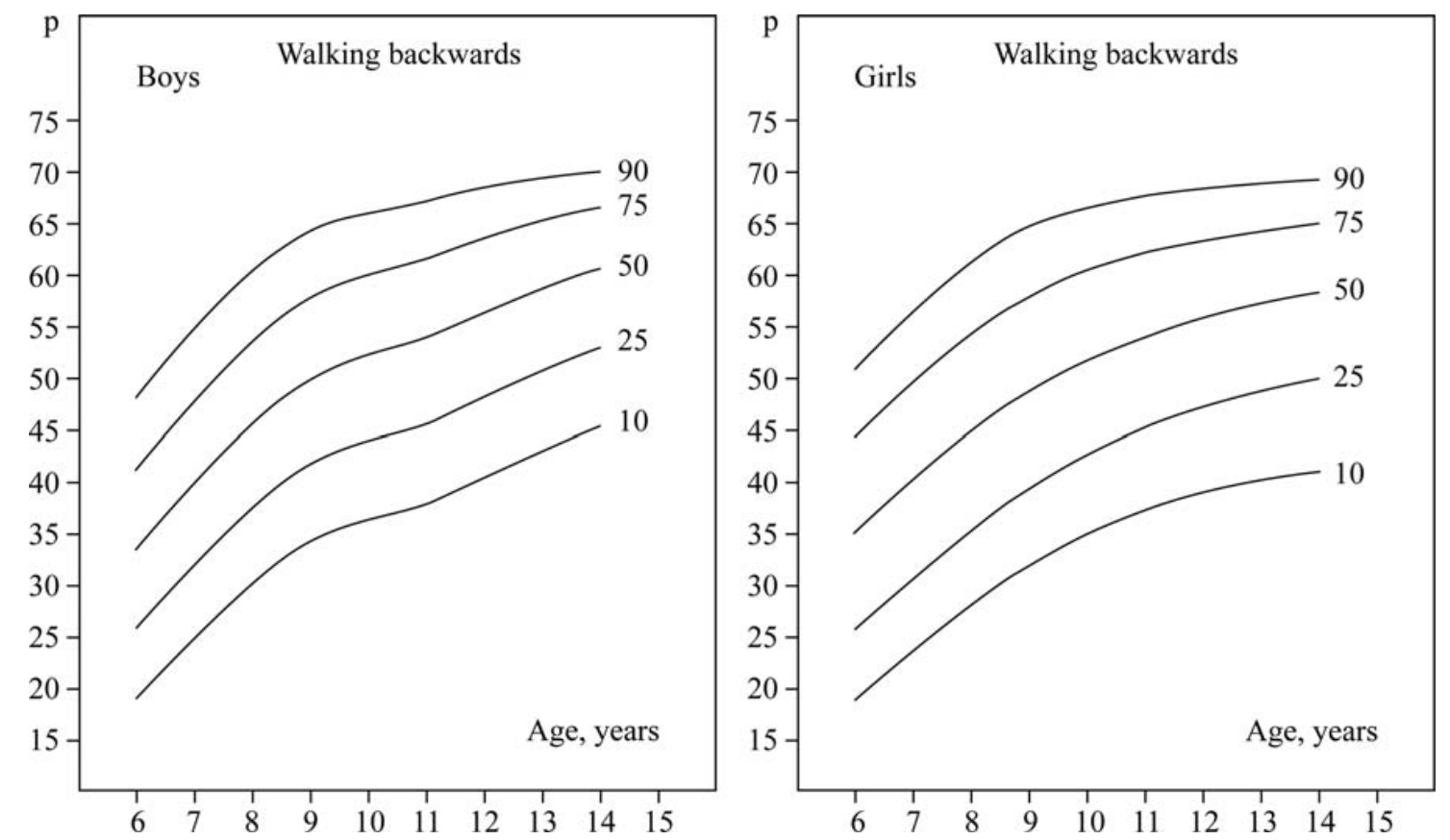

Fig. 1. Centile curves of Portuguese children, aged 6-14 years: walking backwards (Note: $P$ is points).
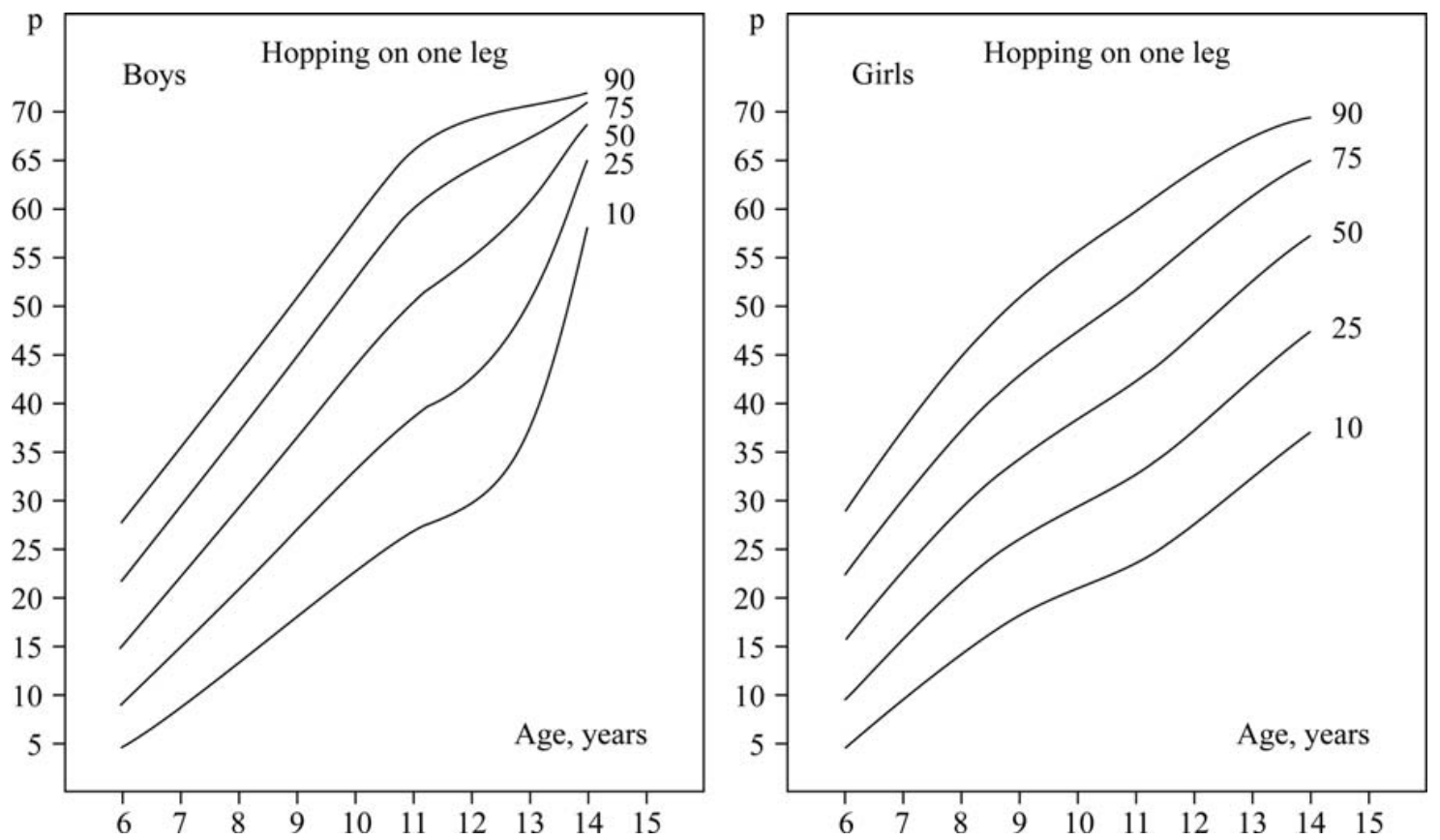

Fig. 2. Centile curves of Portuguese children, aged 6-14 years: hopping on one leg (Note: $P$ is points).

Organization Multicentre Growth Reference Study Group (Borghi et al., 2006) provided good results in the construction of the world standard child growth curves. The setting of the study is also important. It was undertaken in Madeira and Porto Santo Islands at a time of rapid and substantial social and economic change. Since the 1980s, the economy has changed from one based on fishing and agriculture into an off-shore tourist/business center. The population is relatively homogenous; there is no aboriginal population that preceded the Portuguese settlement of the early fifteenth century. Therefore, the large sample size and the random sampling procedure ensured the 

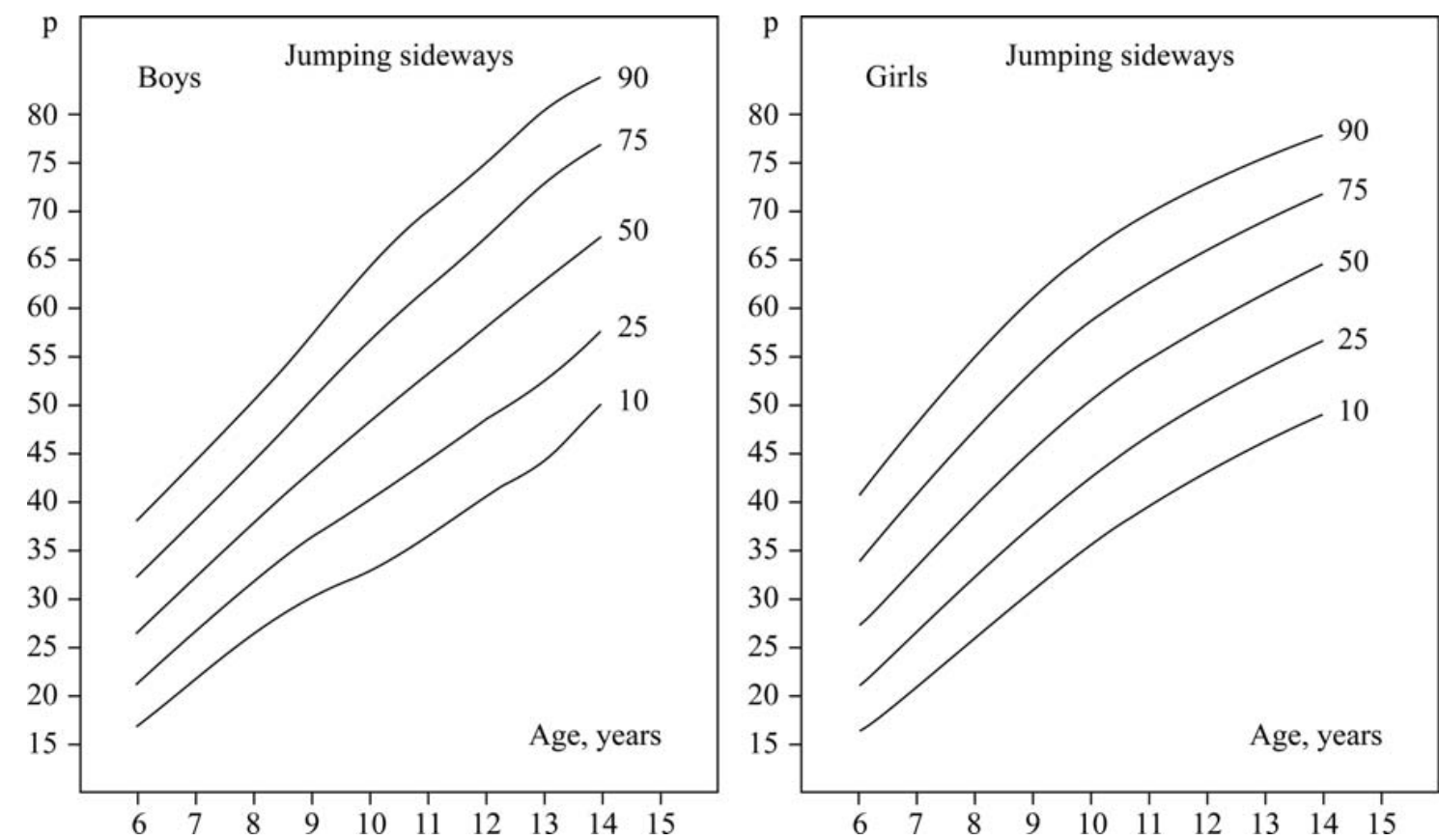

Fig. 3. Centile curves of Portuguese children, aged 6-14 years: jumping sideways (Note: $P$ is points).
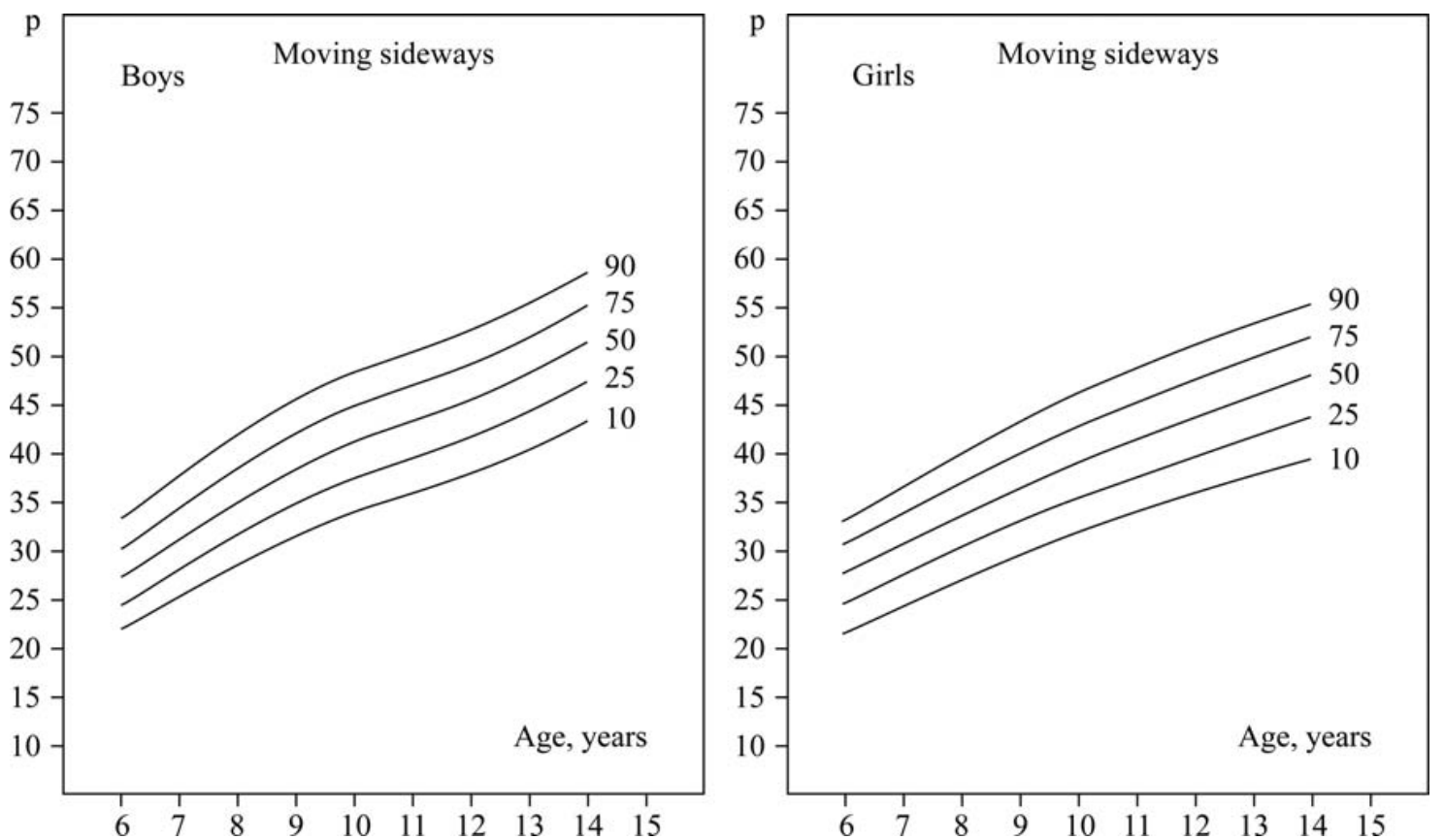

Fig. 4. Centile curves of Portuguese children, aged 6-14 years: moving sideways (Note: $P$ is points).

representativeness of the Portuguese population. In addition, the number of health characteristics available allowed for a clear description of the sample. Finally, the low prevalence of overweight and obese children is an added value when deriving the gross MC curves. However, there are some shortcomings that apply to the current research. First, the cross-sectional nature of this study cannot provide a real picture of the trajectories across time. Second, 
TABLE 3. Gross motor coordination tests (KTK) of normal-weight, overweight and obese children, aged 6-14 years

\begin{tabular}{|c|c|c|c|c|c|c|c|c|}
\hline \multirow[b]{2}{*}{ MC tests } & \multicolumn{6}{|c|}{ Weight status $^{\mathrm{a}}$} & \multirow[b]{2}{*}{$P$} & \multirow[b]{2}{*}{ Contrast } \\
\hline & $n$ & Normal-weight (1) & $n$ & Overweight (2) & $n$ & Obese (3) & & \\
\hline \multicolumn{9}{|l|}{ Boys } \\
\hline \multicolumn{9}{|l|}{$6-8$ years } \\
\hline Walking backwards & 114 & $43.75 \pm 12.14$ & 14 & $48.50 \pm 10.78$ & 10 & $35.90 \pm 8.80$ & 0.012 & 1 and $2>3$ \\
\hline Hopping on one leg & 114 & $29.77 \pm 12.50$ & 14 & $26.64 \pm 11.69$ & 10 & $18.30 \pm 10.04$ & $<0.001$ & $1>3$ \\
\hline Jumping sideways & 114 & $37.18 \pm 10.62$ & 14 & $38.43 \pm 12.65$ & 10 & $30.20 \pm 5.83$ & $<0.001$ & $1>3$ \\
\hline Moving sideways & 114 & $34.12 \pm 5.53$ & 14 & $34.71 \pm 5.90$ & 10 & $31.40 \pm 5.66$ & $<0.001$ & $1>3$ \\
\hline \multicolumn{9}{|l|}{$9-11$ years } \\
\hline Walking backwards & 154 & $56.06 \pm 9.84$ & 50 & $47.26 \pm 10.02$ & 16 & $41.31 \pm 10.38$ & $<0.001$ & $1>2$ and 3 \\
\hline Hopping on one leg & 154 & $48.01 \pm 12.70$ & 50 & $35.96 \pm 12.26$ & 16 & $28.88 \pm 15.95$ & $<0.001$ & $1>2$ and 3 \\
\hline Jumping sideways & 154 & $54.03 \pm 11.77$ & 50 & $47.04 \pm 12.92$ & 16 & $44.00 \pm 12.76$ & $<0.001$ & $1>2$ and 3 \\
\hline Moving sideways & 154 & $44.21 \pm 5.80$ & 50 & $39.88 \pm 5.50$ & 16 & $38.00 \pm 4.32$ & $<0.001$ & $1>2$ and 3 \\
\hline \multicolumn{9}{|l|}{$12-14$ years } \\
\hline Walking backwards & 190 & $59.25 \pm 9.20$ & 44 & $55.70 \pm 11.18$ & 19 & $53.32 \pm 10.19$ & 0.029 & $1>3^{b}$ \\
\hline Hopping on one leg & 190 & $63.31 \pm 11.24$ & 44 & $54.95 \pm 16.38$ & 19 & $42.95 \pm 15.96$ & $<0.001$ & $1>2$ and $3 ; 2>3$ \\
\hline Jumping sideways & 190 & $66.67 \pm 13.17$ & 44 & $61.70 \pm 14.41$ & 19 & $53.89 \pm 10.18$ & $<0.001$ & $1>3$ \\
\hline Moving sideways & 190 & $50.66 \pm 6.27$ & 44 & $48.59 \pm 8.18$ & 19 & $42.74 \pm 3.28$ & $<0.001$ & 1 and $2>3$ \\
\hline \multicolumn{9}{|l|}{ Girls } \\
\hline \multicolumn{9}{|l|}{$6-8$ years } \\
\hline Walking backwards & 98 & $45.01 \pm 12.79$ & 22 & $37.09 \pm 11.51$ & 10 & $31.70 \pm 8.65$ & $<0.001$ & $1>2$ and 3 \\
\hline Hopping on one leg & 98 & $31.20 \pm 10.87$ & 22 & $17.64 \pm 8.62$ & 10 & $10.80 \pm 9.51$ & $<0.001$ & $1>2$ and 3 \\
\hline Jumping sideways & 98 & $40.05 \pm 12.43$ & 22 & $34.45 \pm 12.79$ & 10 & $27.30 \pm 9.60$ & $<0.001$ & $1>3$ \\
\hline Moving sideways & 98 & $33.63 \pm 5.34$ & 22 & $29.82 \pm 4.97$ & 10 & $27.00 \pm 5.83$ & $<0.001$ & $1>2$ and 3 \\
\hline \multicolumn{9}{|l|}{$9-11$ years } \\
\hline Walking backwards & 160 & $53.69 \pm 11.58$ & 64 & $50.91 \pm 11.75$ & 13 & $40.62 \pm 12.82$ & $<0.001$ & 1 and $2>3$ \\
\hline Hopping on one leg & 160 & $43.37 \pm 13.84$ & 64 & $37.47 \pm 12.69$ & 13 & $23.77 \pm 10.54$ & $<0.001$ & $1>2$ and $3 ; 2>3$ \\
\hline Jumping sideways & 160 & $54.88 \pm 11.78$ & 64 & $52.08 \pm 10.51$ & 13 & $44.62 \pm 13.10$ & $<0.001$ & $1>3$ \\
\hline Moving sideways & 160 & $42.12 \pm 5.53$ & 64 & $39.09 \pm 5.10$ & 13 & $35.38 \pm 4.65$ & $<0.001$ & $1>2$ and 3 \\
\hline \multicolumn{9}{|l|}{$12-14$ years } \\
\hline Walking backwards & 220 & $57.51 \pm 10.25$ & 49 & $53.98 \pm 11.84$ & 10 & $42.30 \pm 11.41$ & $<0.001$ & 1 and $2>3$ \\
\hline Hopping on one leg & 220 & $54.95 \pm 12.65$ & 49 & $46.47 \pm 13.42$ & 10 & $31.80 \pm 17.54$ & $<0.001$ & $1>2$ and $3 ; 2>3$ \\
\hline Jumping sideways & 220 & $63.59 \pm 11.37$ & 49 & $62.39 \pm 11.63$ & 10 & $46.00 \pm 13.89$ & $<0.001$ & 1 and $2>3$ \\
\hline Moving sideways & 220 & $47.70 \pm 6.23$ & 49 & $44.29 \pm 6.40$ & 10 & $38.60 \pm 5.08$ & $<0.001$ & $1>2$ and $3 ; 2>3$ \\
\hline
\end{tabular}

aANCOVA is adjusted for age, age squared, physical activity and educational level of the father or mother; MC, motor coordination; data are mean \pm standard deviation.

${ }^{b}$ Least significant difference (LSD) post-hoc test.

although physical activity was addressed, it was selfreported and questionnaire responses depend on the perception, encoding, storage, and retrieval of information (Shephard, 2003). Third, the means of the MC tests across BMI groups were not statistically controlled for in relation to other physical fitness tests (e.g., strength, speed, endurance, and flexibility).

In conclusion, this study presents age- and genderspecific percentiles for gross MC of Portuguese children. Raw scores improved with age, but a main effect was simply observed on walking backwards and moving sideways. Similarly, boys performed better than girls in the majority of gross MC tests; however, a main effect was only found on moving sideways. Children from this study showed a tendency toward lower scores on hopping on one leg and jumping sideways compared to Belgian and German counterparts, and had similar or higher scores than their Azores and Viseu peers. Patterns of gross MC showed a large interindividual variability. Finally, normal-weight and/or overweight children outperformed their obese peers in almost all gross MC tests. These results are generally consistent with the hypotheses that gross MC improves with age and that gender-related differences depend on age and MC test. Additionally, our hypotheses about BMI and gross MC are partially supported by our findings. These centile curves can be used as reference data for Portuguese children. Being overweight or obese was a major limitation of MC tests and, therefore, of the children's health- and performance-related physical fit- ness. It is suggested that longitudinal studies are needed to capture real developmental changes across time.

\section{ACKNOWLEDGMENTS}

The "Healthy Growth of Madeira Study" was cosponsored by the POPRAM III, within the scope of the European Social Funds, via CITMA and the Professional Qualification Centre. The second phase of this study was co-sponsored by the Government of Autonomous Region of Madeira through the Regional Secretary for Education and Human Resources.

\section{LITERATURE CITED}

Ahnert J, Schneider W, Bös K. 2009. Developmental changes and individual stability of motor abilities from the preschool period to young adulthood. In: Schneider W, Bullock M, editors. Human development from early childhood to early adulthood: Evidence from the Munich Longitudinal Study on the Genesis of Individual Competencies (LOGIC). Mahwah, NJ: Erlbaum. p 45-79.

Baecke JA, Burema J, Frijters JE. 1982. A short questionnaire for the measurement of habitual physical activity in epidemiological studies. Am J Clin Nutr 36:936-942.

Borghi E, de Onis M, Garza C, Van den Broeck J, Frongillo EA, GrummerStrawn L, Van Buuren S, Pan H, Molinari L, Martorell R, Onyango AW, Martines JC. 2006. Construction of the World Health Organization child growth standards: selection of methods for attained growth curves. Stat Med 25:247-265.

Chaves RN, Tani G, Souza MC, Baxter-Jones A, Maia J. 2013. Desempenho coordenativo de crianças: construção de cartas percentílicas baseadas no método LMS de Cole e Green. Rev Bras Educ Fís Esporte 27: 25-41. 
Claessens AL, Eynde BV, Renson R, Gerven DV. 1990. The description of tests and measurements. In: Simons J, Beunen G, Renson R, Claessens A, Vanreusel B, Lefevre J, editors. Growth and fitness of flemish girls-the leuven growth study. Champaign: Human Kinetics. p 21-39.

Cole TJ, Bellizzi MC, Flegal KM, Dietz WH. 2000. Establishing a standard definition for child overweight and obesity worldwide: International survey. BMJ 320:1-6.

Cole TJ, Green PJ. 1992. Smoothing reference centile curves: the lms method and penalized likelihood. Stat Med 11:1305-1319.

D'Hondt E, Deforche B, Gentier I, De Bourdeaudhuij I, Vaeyens R, Philippaerts R, Lenoir M. 2013. A longitudinal analysis of gross motor coordination in overweight and obese children versus normal-weight peers. Int J Obes 37:61-67.

D'Hondt E, Deforche B, Vaeyens R, Vandorpe B, Vandendriessche J, Pion J, Philippaerts R, de Bourdeaudhuij I, Lenoir M. 2011a. Gross motor coordination in relation to weight status and age in 5- to 12-year-old boys and girls: a cross-sectional study. Int J Pediatr Obes 6:e556-e564.

D'Hondt E, Gentier I, Deforche B, Tanghe A, Bourdeaudhuij ID, Lenoir M. $2011 \mathrm{~b}$. Weight loss and improved gross motor coordination in children as a result of multidisciplinary residential obesity treatment. Obesity 19 1999-2005.

Eilers PH, Marx BD. 1996. Flexible Smoothing with B-splines and Penalties. Stat Sci 11:89-102.

Fransen J, Pion J, Vandendriessche J, Vandorpe B, Vaeyens R, Lenoir M, Philippaerts RM. 2012. Differences in physical fitness and gross motor coordination in boys aged $6-12$ years specializing in one versus sampling more than one sport. J Sports Sci 30:379-386.

Freitas DL, Fernandes FJ, Teixeira AQ, Gouveia ER, Maia JA. 2013. Metodologia geral. In: Maia JA, Fernandes FJ, Freitas DL, editors. Crescer com saúde na Região Autónoma da Madeira. Funchal: Universidade da Madeira, Universidade do Porto. p 21-34.

Freitas D, Maia J, Beunen G, Claessens A, Thomis M, Marques A, Crespo M, Lefevre J. 2007. Socio-economic status, growth, physical activity and fitness: the Madeira Growth Study. Ann Hum Biol 34:107-122.

Gentier I, D'Hondt E, Shultz S, Deforche B, Augustijn M, Hoorne S, Verlaecke K, De Bourdeaudhuij I, Lenoir M. 2013. Fine and gross motor skills differ between healthy-weight and obese children. Res Dev Disabil 34:4043-4051.

Graf C, Koch B, Kretschmann-Kandel E, Falkowski G, Christ H, Coburger S, Lehmacher W, Bjarnason-Wehrens B, Platen P, Tokarski W, Prede HG, Dordel S. 2004. Correlation between BMI, leisure habits and motor abilities in childhood (CHILT-Project). Int J Obes 28:22-26

IBM Corp. 2010. IBM SPSS statistics for windows, version 19.0. Armonk, NY: IBM Corp.

Instituto Nacional de Estatística. 1995. Antecedentes, metodologia e conceitos: censos 91. Lisboa: Instituto Nacional de Estatística. p 147.

Kiphard EJ, Schilling F. 1974. Körper-koordinations-test für kinder. KTK Manual. Weiheim: Beltz Test GmbH.

Krombholz H. 2013. Motor and cognitive performance of overweight preschool children. Percept Motor Skill 116:40-57.

Largo RH, Caflisch JA, Hug F, Muggli K, Molnar AA, Molinari L, Sheehy A, Gasser T. 2001a. Neuromotor development from 5 to 18 years. Part 1 timed performance. Dev Med Child Neurol 43:436-443.

Largo RH, Caflisch JA, Hug F, Muggli K, Molnar AA, Molinari L. 2001b. Neuromotor development from 5 to 18 years. Part 2: associated movements. Dev Med Child Neurol 43:444-453.

Largo RH, Fischer JE, Roussonb V. 2003. Neuromotor development from kindergarten age to adolescence: developmental course and variability. Swiss Med Wkly 133:193-199.
w?>Lopes VP, Rodrigues LP, Maia JA, Malina RM. 2011. Motor coordination as predictor of physical activity in childhood. Scand J Med Sci Sports 21: $663-699$.

Lopes L, Santos R, Pereira B, Lopes VP. 2012b. Associations between sedentary behavior and motor coordination in children. Am J Hum Biol 24: $746-752$.

Lopes VP, Stodden DF, Bianchi MM, Maia JA, Rodrigues LP. 2012a. Correlation between BMI and motor coordination in children. J Sci Med Sport 15:38-43.

Lubans DR, Morgan PJ, Cliff DP, Barnett LM, Okely AD. 2010. Fundamental movement skills in children and adolescents. Review of associated health benefits. Sports Med 40:1019-1035.

Malina RM, Bouchard C, Bar-Or O. 2014. Growth, maturation, and physical activity, 2nd ed. Champaing. IL. Human Kinetics Publishers. p 712

Rigby RA, Stasinopoulos DM. 2005. Generalized additive models for location, scale and shape. Appl Statist 54(Part 3):507-554.

Shephard R. 2003. Limits to the measurement of habitual physical activity by questionnaires. Br J Sports Med 37:197-206.

Stasinopoulos DM, Rigby RA. 2007. Generalized additive models for location scale and shape (GAMLSS) in R. J Stat Software 23:1-46.

Stasinopoulos M, Rigby B. 2013. Package 'gamlss.' The library for fitting GAMLSS models.

StataCorp. 2009. Stata statistical software: release 11. College Station, TX: StataCorp LP.

Stodden DF, Goodway JD, Langendorfer SJ, Roberton MA, Rudisill ME, Garcia C, Garcia LE. 2008. A developmental perspective on the role of motor skill competence in physical activity: an emergent relationship. Quest 60:290-306.

Tomkinson GR, Macfarlane D, Noi S, Kim D-Y, Wang Z, Hong R. 2012. Temporal changes in long-distance running performance of asian children between 1964 and 2009. Sports Med 42:267-279.

Valdivia AB, Cartagena LC, Sarria NE, Távara IS, Seabra AFT, Silva RM, Maia JA. 2008b. Coordinación motora: influencia de la edad, sexo, estatus socio-económico y niveles de adiposidad en niños peruanos. Rev Bras Cineantropom Desempenho Hum 10:25-34.

Valdivia AB, Lara RF, Espinoza CB, Pomahuacre SQ, Ramos GR, Seabra A, Garganta R, Maia J. 2008a. Prontitud coordinativa: perfiles multivariados en función de la edad, sexo y estatus socio-económico. Rev Port Cien Desp 8:34-46.

Vandendriessche JB, Vandorpe BF, Vaeyens R, Malina RM, Lefevre J, Lenoir M, Philippaerts RM 2012. Variation in sport participation, fitness and motor coordination with socioeconomic status among Flemish children. Pediatr Exerc Sci 24:113-128.

Vandorpe B, Vandendriessche J, Lefevre J, Pion J, Vaeyens R, Matthys S, Philippaerts R, Lenoir M. 2011. The KörperkoordinationsTest für Kinder: reference values and suitability for 6-12-year-old children in Flanders. Scand J Med Sci Sports 21:378-388.

Vandorpe B, Vandendriessche J, Vaeyens R, Pion J, Matthys S, Lefevre J, Philippaerts R, Lenoir M. 2012. Relationship between sports participation and the level of motor coordination in childhood: a longitudinal approach. J Sci Med Sport 15:220-225.

Vasconcelos MA, Maia JA. 2001. Is there a decline in physical activity? A cross-sectional study in children and youngsters of both gender from 10 to 19 years old. Port J Sports Sci 1:44-52.

Vidal SM, Bustamante A, Lopes VP, Seabra A, da Silva RG, Maia JAR. 2009. Construção de cartas centílicas da coordenação motora de crianças dos 6 aos 11 anos da Região Autónoma dos Açores, Portugal. Rev Port Cien Desp 9:24-35.

Zahner L, Muehlbauer T, Schmid M, Meyer U, Puder JJ, Kriemler S. 2009. Association of sports club participation with fitness and fatness in children. Med Sci Sports Exerc 41:344-350. 